\title{
Research on drilling process technology and parameter optimi- zation in soft coal seam
}

\author{
Weizheng $\mathrm{Wu}^{1,2, \mathrm{a}}$ \\ ${ }^{1}$ National Key Laboratory of Gas Disaster Detecting, Preventing and Emergency Controlling, Chongqing 400037 \\ ${ }^{2}$ China Coal Technology Engineering Group Chongqing Research Institute, Chongqing 400037
}

\begin{abstract}
Due to the low firmness coefficient of soft coal seam and the influence of formation pressure and in-situ stress, it is easy to cause hole collapse in bedding drilling, resulting in low hole forming rate and insufficient hole forming depth, so the drilling technology needs to be improved. This paper focuses on the study of hole forming technology and parameters of bedding drilling in soft coal seam. The research results show that: the key to improve the construction efficiency of bedding drilling in soft coal seam is to improve the slag removal ability of drilling engineering, and the drilling technology of spiral drilling and pressure air slag removal is conducive to improve the drilling depth and drilling effect. The hole forming process and parameters of spiral drilling and pressure air slag removal are systematically described. The drill pipe speed, the coal conveying capacity in the hole, the minimum wind speed of pressure air slag removal and the air supply pressure of slag removal are determined. It is of great practical significance to develop and improve the drilling technology of bedding hole drilling in soft coal seam to improve the gas drainage capacity of coal mine and the drilling depth and rate of bedding hole drilling in soft coal seam.
\end{abstract}

\section{Introduction}

Hole collapse often occurs in the construction of bedding hole in soft coal seam. Due to the low firmness coefficient of coal seam and the influence of formation pressure and in-situ stress, the drilling rate is low and the drilling depth is limited ${ }^{[1]}$. At the same time, the occurrence conditions of coal seam underground are complex, and the drilling tools and construction technology of bedding drilling in soft coal seam still cannot meet the actual needs of coal mining. Therefore, it is urgent to improve the drilling technology and optimize the process parameters.

With the improvement of coal mining depth, coal mine drilling mode of the traditional method is hydraulic slag wet drilling in the high gas, high stress, and soft coal seam. The effect of dry drilling method with machine (screw) slag removal is better, but there are still many factors to prevent drilling, mainly for the following reasons ${ }^{[2]}$ : (1) high gas content and high pressure. With the increase of mining depth, gas dynamic phenomena such as top drilling, jet drilling and sticking in the drilling process increase the difficulty of drilling construction. (2)The coal seam is soft. The coal is soft and easy to be affected by formation pressure and original rock stress, which leads to hole collapse. Especially under special geological conditions, drilling is more difficult. (3)Formation pressure and original rock stress. The influence of formation pressure and original rock stress on drilling is that the stress exceeds the strength of coal body, resulting in coal body damage, hole collapse, deformation or hole wall fracture. The comprehensive effect of the above factors makes the hole forming rate low and the hole forming depth insufficient ${ }^{[3]}$.

Scholars have done a lot of research on the construction technology of spiral drilling. Spiral drilling and compressed air slag removal are conducive to improving the hole length and hole forming rate, but there are still some improvements in the technical ways to improve the hole forming length of soft outburst coal seam and the construction technology and parameters of spiral drilling ${ }^{[4]}$.Secondly, the existing drilling equipment cannot meet the construction requirements of bedding drilling in soft coal seam. In view of the special geological occurrence conditions of soft coal seam, the construction technology can be improved by drilling method and slag removal method. Combined with the existing technical means, this paper carries out the field test in Shanxi Tiandiwangpo mine, aiming at improving the soft coal seam spiral drilling technology and optimizing the drilling process parameters, which has important practical significance in improving the mine gas drainage capacity, improving the drilling depth and drilling rate.

\section{Methods}

\subsection{General situation of Wangpo Mine}

Wangpo Mine belongs to Shanxi Tiandi Wangpo Coal Industry Co., Ltd., located in Wangpo village, Jincheng City,

${ }^{a}$ Corresponding author: wluwyuz@126.com 
Shanxi Province, about $25 \mathrm{~km}$ away from Jincheng city. Wangpo Mine is rich in coal resources, with geological reserves of $358.69 \mathrm{Mt}$, minefield area of $29.25 \mathrm{~km}^{2}$ and designed recoverable reserves of $200.25 \mathrm{Mt}$. The mining method is fully mechanized top coal caving. At present, the design production capacity is $1.50 \mathrm{Mt} / \mathrm{a}$, and it is planned to expand to $3.0 \mathrm{Mt} / \mathrm{a}$.

3 \# coal seam is mine mining coal seam with layered structure, local joints and fissures are relatively developed, coal quality is soft and broken, and gas content is $1.44 \mathrm{t} / \mathrm{m}^{3}$. The thickness of coal seam is $5.9 \mathrm{~m}$ and the dip angle is 0 5 degrees, Anthracite, with stable occurrence, contains a thin layer of gangue, with a thickness of 0-0.4 $\mathrm{m}$ and a local maximum of $0.9 \mathrm{~m}$.

\subsection{Basic principle of spiral drilling}

The drilling construction of bedding hole in soft coal seam is far from enough to ensure the effective slag removal measures. Most of the boreholes fail to reach the expected depth due to the blockage of drilling cuttings and the occurrence of sticking (or holding drilling) ${ }^{[5]}$, which has a great relationship with the selection of drilling methods. Spiral drilling is more suitable for drilling in soft coal seam.

Spiral drilling is a common drilling method in engineering geology and drilling construction. Compared with the ordinary drilling technology, it is more suitable for the drilling construction of soft coal seam. It is a dry rotary drilling method. The spiral blade is welded on the cylindrical rod. After entering the coal seam, the cutting force of continuous action is generated by the pressure and rotation torque. The screw blade of the spiral drill pipe has the mechanism of continuous chip removal. The soft coal chips are taken out of the hole, and the drill bit turns into the coal seam under the action of drilling pressure.

Spiral drilling technology has the advantages of quick slag removal, high drilling stability and clean construction site. The main working principle is: the drill bit moves forward with the coal cutting, and the dry operation hole forming method can effectively avoid the effect of scour liquid on the wall of the hole. In the process of drilling along the soft coal seam, the drilling stability can be improved. During construction, the rotary hydraulic motor of drilling machine rotates with the main shaft under the driving of hydraulic transmission, and the anti-skid bolt connects the front end and the spiral drill pipe of the screw spindle. Under the action of power and torque, the coal chips are continuously brought out with the rotating blades. The continuous coal cuttings bring out to ensure the connectivity and effectiveness of the space in the hole, and gradually release the gas in the hole. It not only solves the problem of hole spraying, but also improves the hole forming rate and safety of drilling construction.

\subsection{Screw drill and matching drilling tools}

The general section of the drilling along the soft coal seam is small, and the distance of the drilling is long and the links are many. The size of the drill is small and easy to handle. The soft coal body is easy to break, and more coal chips are produced, which requires higher slag discharge capacity of drilling rig. For the above reasons, a new suitable spiral drilling machine is needed based on the higher drilling capacity and the requirements for the drilling along the soft coal seam. The screw drilling machine with higher drilling capacity and high speed needs to be equipped with the drilling tools with wind pressure and auxiliary slag discharge. It can not only strengthen slag discharge capacity, but also ensure the safe and effective construction of drilling along the layer. Drilling tools mainly include drill bits and spiral drill pipes. By analyzing the influence of the structure and parameters of the drill bit on the slag production and slag discharge of different hardness, the bit which can reduce the slag block size, is favorable for slag discharging and reasonable structural parameters is selected.

\subsection{Optimization of technological parameters for spiral drilling}

Screw drilling technology can optimize the parameters from two aspects: the calculation of screw drilling speed and the relationship between screw drilling speed and cutting coal. The movement mode of coal chips in the borehole is shown in Fig. 1.

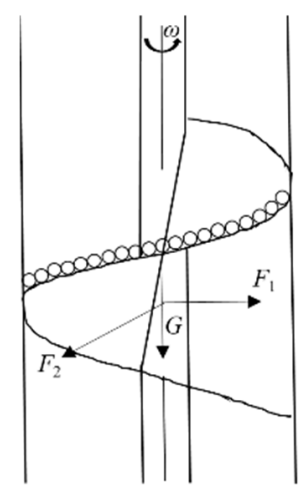

Fig. 1 Movement mode of coal chips in borehole

According to the magnitude, direction and position of action point of cutting resistance (See Fig. 2), $\mathrm{w}_{\mathrm{r} 1}$ equation of critical angular velocity and $\mathrm{Wr}_{2}$ equation of relative angular velocity of coal chips to borehole wall when coal chips slide along borehole wall, the calculation is carried out. The calculation formulas are as follows (1) and (2)

$$
\begin{gathered}
\omega_{r 1}^{2}=\frac{g\left(\frac{K}{G}+f_{1} \cos \alpha+\sin \alpha\right)}{f_{3}(R-r)\left(\cos \alpha-f_{1} \sin \alpha\right)} \\
\omega_{r 2}^{2}=\frac{g\left(\frac{K}{G}+f_{2} \cos \alpha+\sin \alpha\right)}{f_{4}(R-r)\left(\cos \alpha+f \sin \alpha_{2}\right)}
\end{gathered}
$$

Where: $\alpha$-helix angle, ${ }^{\circ} ; \quad K$ - adhesion coefficient; $f_{1}$ - friction coefficient of coal debris to spiral blade in rolling state; $f_{2}$-Friction coefficient of coal debris to spiral blade under sliding state; $f_{3}$ - rolling friction coefficient of coal debris relative to the hole wall; $\mathrm{G}$ - gravity of coal debris, $\mathrm{N}$; $\mathrm{R}$ - radius of drilling, $\mathrm{m}$; $r$ - coal chip radius, $\mathrm{m}$. 


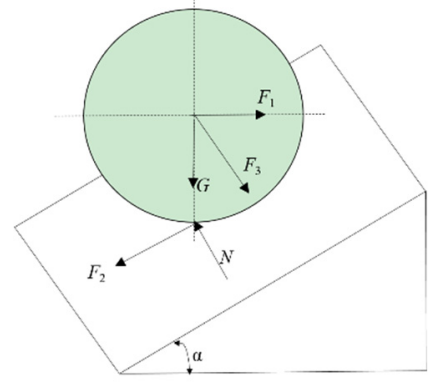

Fig. 2 mechanical model of coal chips

Because the working speed of the spiral drill pipe is limited, the higher the speed of the spiral drill pipe is, the greater the centrifugal force of the coal chips generated after cutting the coal body, that is, the greater the pressure of the coal chips acting on the hole wall. At this time, the coal chips will rotate with the spiral drill pipe, and will not be transported. Therefore, there should be a certain limit value for the rotation speed of the spiral drill pipe, but this limit value is not necessarily the maximum value of the conveying capacity. The purpose is to determine that there is a rotation speed to make the conveying capacity maximum. Generally, the speed $\mathrm{n}$ should meet the following equation (3)

$$
n \leq \frac{43.2}{\sqrt{D}}
$$

Where: $\mathrm{n}$-speed, m/s; D-diameter of borehole, $\mathrm{m}$.

When the actual rotation speed $\mathrm{n} 1$ of the spiral drill pipe conforms to the following equation (4), the conveying capacity of the spiral drill pipe is the maximum.

$$
n_{1}=\frac{n}{2} \leq \frac{21.6}{\sqrt{D}}
$$

\section{Results \& Discussion}

\subsection{Basic principle of compressed air slag re- moval}

The slag discharging method is mainly by pressing air and washing with water. Traditional washing and slag discharging method has a great impact on the hole wall due to the water pressure. However, the firmness coefficient of soft coal is low, and the coal body is generally broken and the bearing capacity is poor. Under the impact of water pressure, it is easy to produce the phenomenon of expanding and spraying holes. At the same time, because the porous medium structure of the loose coal has strong adsorption effect, the gas seal is blocked in the pore fracture structure, which hinders the gas flow transmission.

The pressure wind and slag discharge are more suitable for the construction technology of drilling in soft coal seam. First, the way of pressure air slag removal avoids the damage of washing slag discharge method to soft coal due to the water pressure. Secondly, the pressure air slag discharge has the advantages of stability, safety and efficiency. High speed air flow can not only bring out coal debris, but also cool the drill bit. But its shortcomings are also obvious, because the wind flow is not easy to control, easy to form dust. The two kinds of slag discharging methods are analyzed comprehensively, and the pressure wind slag discharging method is more suitable for the construction requirements of the drilling in soft coal seam.

\subsection{The technical way to increase the length of hole in soft outburst coal seam}

The construction effect of drilling along seam extraction in Wangpo mine is not ideal, which is mainly manifested in the serious hole collapse of coal seam drilling, so the drilling tools are required to have greater slag removal capacity. However, the existing drilling technology is far from enough to ensure effective slag removal measures, and the vast majority of drilling holes fail to reach the expected depth due to drilling cuttings blocking and sticking (or holding drilling). Secondly, the existing drilling equipment, such as drilling rig and drilling tools, cannot meet the construction requirements of long drilling along the formation. Therefore, the construction of bedding long drilling should start with the study of effective slag removal technology and appropriate technical parameters, and the selection of large capacity drilling equipment suitable for the conditions of bedding drilling construction.

Spiral drilling technology is a kind of drilling technology for gas pre drainage in soft and outburst coal seam, which is based on the mechanism that the bit cuts coal body forward and the spiral blade of spiral drill pipe continuously removes cuttings. And then, compressed air slag removal is a better way to drill in outburst or soft coal seam. In view of the characteristics of compressed air slag removal and the actual conditions of drilling in outburst coal seam, the construction test of long drilling along the seam in soft coal seam is mainly carried out by means of spiral drilling compressed air slag removal.

\subsection{Influencing factors of slag removal by com- pressed air}

The effect of pressure air slag removal mainly depends on the wind speed and air volume. According to the effect of pneumatic conveying, whether the coal cuttings produced by drilling can be blown out depends on not only the wind speed in the hole, but also other inherent physical properties, including drilling angle, drilling diameter and drilling depth.

The drilling angle is designed according to the requirements of extraction, which directly affects the efficiency of slag removal. The larger the angle is, the better the slag removal effect will be with the action of gravity. When the drilling angle decreases, the air supply should be increased appropriately, so as to ensure that the air flow in the drilling hole is sufficient and maintain sufficient wind speed; The larger the cross-sectional area of the borehole, the greater the air resistance of the borehole wall. Therefore, the inlet air volume should be appropriately increased to ensure sufficient wind speed. The greater the drilling depth is, the longer the drill pipe is, and the greater the wind resistance in the hole is. Therefore, with the increase of drilling depth, the wind pressure should be increased to prevent the occurrence of coal accumulation and hold drilling. 


\subsection{Optimization of process parameters for pres- sure air slag removal}

(1) Minimum wind speed for slag discharge

A large number of particles are produced continuously in the actual drilling, and the mutual obstruction between them may lead to blocking. In order to ensure that the cuttings in the borehole are not blocked, the air flow velocity should also meet the following conditions: minimum air velocity for slag removal:

$$
\begin{gathered}
u_{a}=u_{t} \sqrt{\zeta_{\mathrm{s}} \cos \theta+\sin \theta} \\
u \geq u_{b}=10 \cdot \sqrt[5]{39.6 \frac{\mathrm{Ws}}{\rho_{\mathrm{a}}}}
\end{gathered}
$$

Where: $u_{a}$-for the minimum air velocity of cuttings particles, $\mathrm{m} / \mathrm{s} ; \zeta-$ the friction coefficient between the cuttings and the hole wall, taking the maximum value of $1 ; \theta$ The dip angle of the borehole is negative for the upward hole and positive for the downward hole. In the formula, $u$ - the actual air velocity is the wind velocity at the orifice, $\mathrm{m} / \mathrm{s} ; u_{b}-$ minimum wind speed satisfying non-blocking condition, $\mathrm{m} / \mathrm{s}$; WS - slag yield, $\mathrm{kg} / \mathrm{s}$.

Therefore, the maximum value of $u_{a}$ and $u_{b}$ should be taken as $u=\max \left\{u_{a}, u_{b}\right\}$ to ensure normal slag discharge.

2) Pressure of air supply for slag discharge

Slag discharge not only needs to achieve the minimum wind speed, in order to make the wind speed reach the minimum wind speed, the air flow needs to overcome the loss caused by various air flow resistance, so the air supply pressure needs to be considered. The air flow loss $\triangle \mathrm{P}$ is generally composed of the following parts: the resistance loss $\triangle \mathrm{P}_{\mathrm{a}}$ of pure air flow from the bottom of the hole to the hole, the additional resistance loss $\Delta \mathrm{P}_{\mathrm{sac}}$ of drilling cuttings accelerating from the bottom of the hole to a certain speed, the additional resistance loss $\triangle \mathrm{P}_{\mathrm{S}}$ of coal slag conveying at a certain speed and discharging to the hole The pressure wind resistance loss $\Delta \mathrm{P}_{\mathrm{t}}$ of bit and the resistance loss $\triangle \mathrm{P}_{\mathrm{z}}$ of air flowing in drill pipe. So,

$$
\Delta P=\Delta P_{a}+\Delta P_{s a c}+\Delta P_{s}+\Delta P_{t}+\Delta P_{z}
$$

If the wind speed in the borehole is $\mathrm{u}$, the air supply flow is:

$$
Q_{a}=\pi / 4\left(D_{h}^{2}-D_{d}^{2}\right) u
$$

Where: $Q_{a}$ - air supply flow, $\mathrm{m}^{3} / \mathrm{s} ; D_{h}$-borehole diameter, $\mathrm{m} ; D_{d}-$ outer diameter of drill pipe, $\mathrm{m}$.

\section{Conclusions}

(1) The drilling technology of spiral drilling and pressure air slag removal has the advantages of improving drilling depth and drilling efficiency, which is suitable for bedding drilling construction in soft coal seam.

(2) This paper systematically expounds the hole forming technology of spiral drilling and pressure air slag removal, optimizes the drilling construction parameters, determines the rotation speed and conveying capacity of spiral drill pipe, and gives the minimum wind speed and air supply pressure of pressure air slag removal.
(3) It is of great practical significance to improve the gas drainage capacity of the mine and the depth and rate of drilling along the seam in soft coal seam.

\section{References}

1. Yuning Sun, Yonglong Wang, Xinxian Zhai, et al., Analysis on reasons of drilling difficulty in soft and outburst coal seam [J]. Journal of China Coal Society, 2012, 37(01): 117-121.

2. Dayong Tang, Zhihong Wang. Research of Drill ing Equipment and Craft for Soft-extrude Coal along Level Bed [J]. Coal mine machinery, 2009, 30(11): 52-54.

3. Zhangguo Huang. Characteristics of hole circle coal body deformation and cuttings generating in deep soft coal seam drilling [J]. Coal Engineering, 2020, 52(04): 92-96.

4. Jingguo Wang, Haitao Mo, Xin Jin. Application of spiral drilling technology in soft coal seam [J].Safety in Coal Mines, 2007(11): 27-29.

5. Jianqiang Wang. Application of Flushing Fluid in Gas Drainage Drilling of Soft Coal Seam [J]. Safety in Coal Mines, 2019, 50(06): 28-31. 